\title{
Immigrant and Non-immigrant Parents' Involvement in Bullying Cases
}

\author{
Hildegunn Fandrem ${ }^{1}\left[\right.$. Janne Støen ${ }^{1}$
}

Accepted: 10 September 2021 / Published online: 23 September 2021

(c) The Author(s) 2021

\begin{abstract}
This study aims at investigating parental involvement in bullying cases. Immigrant and non-immigrant parents are compared regarding their experience and understanding of causes of the bullying behaviour that their child is exposed to, how they experience the school's handling of the bullying case, the home-school cooperation, and parents' cooperation with other parents. A qualitative approach was used, and semi-structured interviews with 16 parents of targets of bullying were carried out (5 immigrant, 11 Norwegian, including two Sami parents). The targets were from primary and lower secondary school. Content analysis was conducted using the deductively developed and inductively enriched system of categories. The results of the study provided insights into parents' experiences of a problematic school-parent collaboration, and also problematic relations to the other parents of the students involved in the respective bullying cases. Immigrant parents were more satisfied with the school than non-immigrant parents, but not with the relation to other parents. Vulnerability and ethnicity-based bullying appeared as aspects which should be paid especially attention to, regarding both implications and future research.
\end{abstract}

Keywords Bullying cases $\cdot$ Parental involvement $\cdot$ Immigrant parents $\cdot$ Home-school cooperation

As there is an ongoing debate among scholars about how to define bullying (Thornberg \& Delby, 2019; Fandrem, et al., 2021), the phenomenon has for several decades now been considered a complex relationship problem, and the most used definition still includes the three criteria: (1) intentional harmdoing, (2) imbalance of power, and (3) repetition over time. Using this, or related definitions, in schools and for research purposes, research show that the prevalence of bullying varies from country to country (Craig et al., 2009); however, it seems that the number of students being bullied at school is quite stable. In Norway, the rates have been approximately 5\% in recent years (Wendelborg, 2020), which is comparable to other Western EU countries.

The ecological systems theory developed by Bronfenbrenner $(1979,2005)$ has in the past decades been used by several researchers to describe how different individuals and contexts are involved in the complex social phenomenon of bullying (Espelage \& Swearer, 2004; Rivara \& Le Menestrel, 2016; Støen et al., 2018; Peguero \& Hong,

Hildegunn Fandrem

Hildegunn.fandrem@uis.no

1 Norwegian Center for Learning Environment and Behavioural Research in Education, University of Stavanger, Stavanger, Norway
2020). Within this theoretical framework, individual behaviour is considered to be jointly influenced by a variety of ecological contexts, such as the peer context, the schoolteachers, the family, and other adults in the wider community. The systems closest to the child, like their peers, parents, and teachers, are found on the micro level. When these systems relate, or collaborate with each other, e.g., home-school collaboration, we talk about the meso-level. The macro level consists of systems further away from the child, such as school owner, the laws, and even the norms and values of a society may be said to be contextual factors at this level. Studies have documented that the actions of the individuals in these contexts are implicated in both the development and maintenance of bullying, and thus, they are important for intervening against bullying (Støen et al., 2018). The different systems influence the children's behaviour, or work with the bullying case, directly or indirectly.

Most previous research on bullying is focused on the children who are involved: those who bully, those who are targets, and the bystanders. To date, there has been little research on the perceptions and understanding of the parents of the children who are involved in bullying. The little research that has focused on the adults involved in the child's or adolescents' life has mostly examined the perspectives of teachers (Bernstein \& Watson, 1997; Borg, 1998; Boulton, 
1997; Flaspohler et al., 2009; Mishna et al., 2005). The first studies on parents investigated to what degree parents may be held responsible for bullying; thus, home conditions like SES and family functioning, as well as parenting style, e.g., emotional attachment between parents and children, were investigated (Baldry \& Farrington, 2000 et al., 2000, Ladd \& Kochenderfer Ladd, 1998, Olweus, 1980; Smith \& Myron-Wilson, 1998, Troy \& Sroufe, 1987). Later studies maintained this focus; e.g., Georgiou and Stavrinides (2013) found a correlation between conflict between parents and children's aggressive behaviour, such as bullying in school. Such approaches have mostly used a quantitative design, and they point to explanations for bullying and the importance, or role, of upbringing with regard to being either a perpetrator or a victim of bullying. More recently, researchers have, however, shown more interest in the experiences and perspectives of parents whose children have been involved in bullying. Mishna and colleagues (2006) were, as far as we know, the first to investigate parents' view using a qualitative approach. They interviewed 20 parents of targets of bullying in grades 4 and 5 and found that many referred to children trying to make a child feel "down," "lower," or in a "lesser category." However, several parents also reconsidered how they perceived particular incidents after hearing the definition of bullying provided by the researchers. Sawyer et al. (2011) claim that parents need to increase their understanding of what bullying is to be conscious of the important role they have in protecting their children (and other children) from bullying. However, when parents are included in research as informants, they are often asked to complete questionnaires about victimization on their child's behalf (Holt et al., 2007; Nordhagen et al., 2005). Recently, and in line with Bronfenbrenner's bioecological model (2005), research has emphasized that bullying is affected by complex relationships among individual factors, home conditions, peer relations, and aspects related to the school and to the society as a whole (Hein, 2012; Nickerson et al., 2010). Thus, we may claim that also cooperation between parents and the school, both regarding bullying cases and in general, is necessary to resolve and prevent bullying cases.

The aspect of parent involvement that concerns communication and cooperation with the school is, however, a dimension that has received very little attention. To further understand the influence of these micro and meso systems in Bronfenbrenner's theoretical framework, cooperation between parents also requires attention when striving to create a bully-free school environment. The main aim of this study is thus to gain a deeper understanding of how parents of targets of bullying experience cooperation with the school and with other parents.

An important macro level factor in Bronfenbrenner's framework is culture or cultural values. We know, e.g., that regarding bullying the concept used in Japan, 'ijime' imply that the bullying is a collective action, and thus performed by several students together, while the bullying-concept as it is mostly used in western cultures include also one-to one behaviour (Kanetsuna, 2016). Coming from an individualistic or collectivistic culture may also influence to which degree one expects collaboration. As we have both immigrant and non-immigrant parents in our sample, we wanted to compare the two groups of parents regarding their interpretations of causes of bullying, collaboration with school and collaboration with each other regarding bullying cases. As far as we know. this has not been previously investigated. Immigrant parents' involvement in bullying cases has not, to our knowledge, been previously investigated either, only involvement in general (Antony-Newman, 2018). We also know from previous research that immigrants might face some psychosocial challenges (Berry, 1997), they might be more vulnerable for being bullied, and results show that immigrants actually are more bullied for their race or ethnicity (Fandrem et al., 2021; Stevens et al., 2020). As a consequence, bullying intervention programs might need specific elements towards this group. Thus, it was of special interest to compare immigrant and non-immigrant parents in this study.

\section{Parental Involvement in Schools}

Regarding parental involvement in general, Moorman Kim and Sheridan (2015) claim that outreach to parents may be structural, i.e., structured around activities demonstrated by parents to provide support for their child's education (p. 3), or it may be relational, whereby families and professionals collaborate to enhance opportunities and success for students across social, emotional, behavioural, and academic domains. It is the relational perspective that is of relevance in the present study.

Moreover, the most common classification of parental involvement by type was offered by Epstein (2010), who combined psychological, sociological and educational perspectives on the cooperation among families, schools, and local communities. She distinguished six types of parental involvement: (1) parenting: help given by the school to families regarding their parenting skills and the creation of a home environment conducive to learning; (2) communicating: regular exchange of information between schools and parents about the curriculum and students' progress; (3) volunteering: encouragement of parents to participate in school activities; (4) learning at home: support of parental help with homework and other curriculum-related activities; (5) decision making: involvement of parents in school management; and (6) collaborating with the community: identification and coordination of community resources to aid parenting and learning at school. Although this 
framework is based on schools as the active agents and parents as more passive (Stitt \& Brooks, 2014), it may be useful because in all six types of involvement, parents have the potential to show initiative and engage with schools. The framework has also learning as a focus; however, there is a close relationship between academic learning and social factors (Farrington et al., 2012; Pellegrino \& Hilton, 2012; Skeie \& Fandrem, 2021). Thus, the framework may also be applicable for work on bullying cases in school. More specifically, Kirkhaug et al. (2013) emphasize that children who have parents that actively support their schoolwork seem to have better peer relations; they are more confident and have better school performance than children who do not have the same parental support.

Previous research on cooperation between parents and the school in general is scarce, but some studies have examined problematic issues. Westergard (2010) investigated in her qualitative study, where 16 parents and teachers were interviewed, what characterizes situations with difficult cooperation, she found that parents often experienced cooperation as problematic; they reported disillusionment towards school, while the teachers involved described it as satisfactory. In some cases, worried parents were described as opposing and difficult, and instead of being taken seriously, they were a source of stress for teachers. In addition, Westergard (2004) found in her quantitative study among 1569 parents that parents of low socioeconomic status were likely to report more disillusionment with the school than parents of high socioeconomic status. This may imply that schools and teacher do not manage to meet different parents' needs or it may be said to represent a culture in which it is difficult for some parents to participate because it is strange and unfamiliar to them (Støen et al., 2018). No studies were found regarding parents' collaboration with other parent collaboration in school.

\section{Parental Involvement in Bullying Cases}

Hein $(2012,2016)$ investigated how parents may be understood and positioned as actors in bullying cases and their opportunities and experiences regarding their potential to adopt influencing measures. More specifically, she described, in her qualitative research how intense encounters between teachers and principals on one side and parents and children on the other can become entangled in conflict and mutual frustration. Further, researchers claim that this occurs as a result of school-initiated attempts to define the children's reality in school and the truth about what has happened, with the intent of pointing out what the parents have done wrong to cause their children to behave as they do (e.g., Søndergaard, 2020). Thus, the focus is on the problem with the student and the home conditions more than the social context in which the bullying occurs and in the interactions between systems. With this as the base, mistrust is fostered, and it is difficult to collaborate to solve difficult situations. In the study of Hein (2012), parents experienced that when they approached the school with concerns about their own child being bullied, their parenting style was questioned. Additionally, in their meta-analysis, Harcourt and colleagues (2014) found frequent miscommunication, misunderstanding, and misjudgement of bullying situations between parents and the school.

One more recent study that we found on parent involvement in bullying cases was from Hong Kong and presented a list of good practices for positive home-school cooperation in addressing bullying (Liu, et al. 2019). The study particularly emphasizes the importance of including parents both while addressing bullying and after the closure of the case. Moreover, the authors claimed that parents' timely interaction with their children after school has finished, continued communication with teachers, and active offering of feedback to the teachers all especially contribute to the smooth and effective resolution of bullying cases.

\section{Challenges Related Specifically to Being an Immigrant}

The recent meta-synthesis of Antony-Newman (2018) regarding the parental involvement of immigrant parents found that most previous studies investigated one specific immigrant group, e.g., Latino Greeks or Jews, and they used interviews as the main data source. Moreover, the review found that because immigrant students often fall behind their native-born peers in academic achievement (OECD, 2015), parental involvement by immigrant parents is lacking, as is genuine inclusion of immigrant parents, whose cultures and experiences are often set aside. Most relevant for our study is that there is a mismatch between the frames of reference of teachers, who are predominantly natives and thus represent the dominant culture, and those of parents with immigrant backgrounds, who have different educational experiences (i.e., immigrant parents are often lower educated than native parents), and different expectations of parental involvement in school (i.e., parental involvement less expected in collectivistic compared to individualistic oriented cultures). Language barriers and insufficient familiarity with the educational system are emphasized by Antony-Newman (2018) as the two main obstacles.

Not only cultural orientation (Hofstede, 1984) but also being a minority (Rogers \& Lange, 2013) or having a migration experience may have consequences for the interpretation of what is happening and what is expected regarding cooperation (Antony-Newman, 2018). Having a migration experience may make one more vulnerable regarding the establishment of relationships (Berry, 1997) and thus 
cooperation. The international literature implies that parents of immigrant children experience to a lesser degree that the school initiate collaboration with them (Cherng, 2016), and they generally encounter more barriers in cooperation with the school (Turney \& Kao, 2009). In a very recent study investigating top-level policies across Europe regarding newly arrived immigrants, Meehan and colleagues (2021) found that the engagement of parents seemed largely to depend on the awareness, initiative and resources of the local school administrations, leaders, and classroom teachers.

Regarding immigrant-specific factors related to bullying behaviour, the reasons underlying bullying have long been a focus of research. Results have shown that power-related and affiliation-related aggressiveness is associated with bullying others (Fandrem, et al., 2009; Roland \& Idsoe, 2001). Moreover, regarding the characteristics of those who are targets, having poor social skills, having few friends, being socially rejected by one's peers, and having physical characteristics that distinguish a person from the rest of the peer group are found to be risk factors. These findings highlight that being a target of bullying significantly relates to those characteristics that other children think set a child apart from the rest of the peer group, such as how they appear or how they behave, i.e., are different. These findings have led to an increased focus on ethnicity-based bullying, which is a subtype of identitybased bullying. Identity-based bullying is defined as negative behaviour towards particular social groups, justified on the basis of their identity (Tippett, et al., 2010). It arises as a result of people's poor understanding of diversity and a lack of confidence among school staff in discussing issues related to, in our case, ethnicity-based characteristics. In Norway, general bullying research has a long tradition, the first studies were conducted in the early 1970s (Olweus, 1974), the first international published study on bullying among immigrants were published in 2009 (Fandrem et al., 2009), but only recently the focus have been on identity-based bullying (Skeie \& Fandrem, 2021). No previous research has investigated whether identity-based aspects might be explanations for problematic relations between teachers and parents or between parents.

\section{The Present Study}

In this study, parental involvement in bullying cases encompasses (1) parents' interpretation of the bullying behaviour; (2) parents' cooperation with the school about the bullying, with a specific focus on how the school handled the bullying case; and (3) parents' cooperation with other parents. We first examined how the parents viewed the bullying their children were exposed to, i.e., the understanding of the sources behind the negative behaviour, including their thoughts about its causes and consequences. Then, we investigated the cooperation between parents and the school in the specific bullying cases. We explored in particular how parents felt they were treated when they informed the school that their child had been bullied or to share their experience in those cases where the school had identified or defined what was happening as bullying. Last, we investigated the parents' cooperation with other parents involved in the same bullying case. No previous research is found on this last topic, but as it theoretically is found as a factor in Bronfenbrenners' framework on meso level, we anticipate that also this will influence the child. As we have both Norwegian and immigrant parents in our sample, and immigrants might interpret things differently compared to non-immigrants as showed above, we pay specific attention to, or adopt a comparative approach to, the role of parents' immigrant background.

The following research questions were formulated:

- How do Norwegian and immigrant parents of targets of bullying experience and understand the bullying behaviour that their child is exposed to?

- How do Norwegian and immigrant parents of targets of bullying experience the school's handling of the bullying case and home-school cooperation?

- How do Norwegian and immigrant parents of targets of bullying experience cooperation and communication with other parents regarding the bullying case?

As little research exists on this topic, we had few hypotheses in advance. Based on the previous mentioned studies it could, however, be hypothesized, regarding our first research question, that there might be different understandings between immigrants and non-immigrant parents, related to whether it is a collective action from several students to one student, and that also more actions will be interpreted as bullying among the immigrants, because they are in a vulnerable situation. Regarding our second research question, there might be differences because immigrant parents might not expect that there should be any collaboration with school; thus, they would be happily surprised when teachers inform them about what is happening in a bullying case and want collaboration. On the other hand, as collectivistic cultures are more relational focused, immigrant parents might expect more social interactions with both school and other parents, but it might also be difficult for them to interact with others because of language barriers and a possible vulnerable situation. Thus, we could not draw any clear hypothesis for the direction of the difference between immigrant and non-immigrant parents regarding research question two and three. 


\section{Method}

\section{Data Collection}

We conducted individual semi structured in depth interviews. Convenience sampling was used, as the bullying cases, from where targets and thus parents were selected, were identified through collaborators (principals of schools or employees of educational psychology services) of the Norwegian Center for Learning Environment and Behavioral Research in Education. The principals at the selected schools were contacted by telephone and email. The purpose of the study was explained on a written information sheet, which also included the ethical guidelines. The parents of the targets at the different schools were then contacted by the principal at the school their bullied child attended. Before the interview started, the informants were informed that the data would be anonymized and that they could withdraw from the research at any time without adverse consequences. The parents were also presented the following definition of bullying "We call it bullying when one or more persons over time are aggressive towards another person who has difficulty defending him- or herself" to ensure that they were aware that it was bullying behaviour that was the focus of the study. The interviews were conducted by three researchers and they took place at the local school, at the local library or in the parents' home. The interviews lasted between 45 and $90 \mathrm{~min}$, and they were audio recorded and transcribed verbatim by external transcribers. Based on information from the school about the parent's fluency in Norwegian, we used professional interpreters in two of the interviews.

\section{Participants}

The participants were 16 parents of targets of bullying, which was a necessary sample size to reach saturation. Eleven of the targets were Norwegians, 10 of these were girls, and one was boy. Two of the Norwegians were Sami and Sami with mother from the Philippines; these two were thus characterized as having another ethnic background compared to the other Norwegians. The four mothers, six fathers and one couple, were all biological parents, except from one, the father of one of the Sami children. Of the five targets that had immigrant background, four were boys and one was a girl, they or their parents had migrated from Afghanistan, Germany, Lithuania, Russia and Poland. The immigrant parents, four mothers and one father, were also biological parents.

The targets were selected based on cases identified by the principal as bullying cases. The bullying was both face to face, but also some episodes of cyber-bullying. The identified bullying cases had been dealt with for 1-7 years, and most were characterized as difficult to solve, but at the time of the data collection, they were officially closed; i.e., the case was interpreted by the school as solved, but not necessarily in a good way. Some cases were closed because the pupil moved to another school, or because of the change from primary to lower secondary school.

The cases were from primary and lower secondary schools, more specifically the children were between 8 and 14 years old. The parents were drawn from 12 different schools; five of the parents were involved in the same bullying case. The Norwegian parents were interviewed in 2014, while the immigrant parents were interviewed in 2018; the 4-year difference was due to the addition of a sub project focusing on immigrants after the main project had started.

\section{The Instrument}

The interview guide was the same in all cases but with some additional questions when relevant to the specific case and when the informant had an immigrant background. It first included some initial questions about the background of the targets and their situation now. We presented a definition of bullying and then asked about how they had come to know about the bullying of their child; if their child itself talked about it, what they knew and how they interpreted what had happened. We also asked about what they thought about measures taken by the school. We asked more in depth about the cooperation with the school, and also about cooperation with other parents. The questions were open to let the informants decide what they themselves wanted to tell. If the parent was an immigrant or a minority parent we asked about their thoughts regarding ethnicity as an aspect; both to which degree they thought ethnicity influenced what was happening between the one who bullied and the target (e.g. "Do you think it happened because he [the child] had another ethnic background?") and if ethnicity influenced the collaboration the parent had with either school or other parents (E.g. "Do you think it was like this because of your ethnic background?").

\section{Data Analyses}

Thematic analysis was used to analyse the data. Two researchers, both females and Norwegian, read through the interviews twice and then did the analyses together. One of the researchers, the one who did all the interviews with the immigrants, has worked in the immigrant research field for several years and has thus considerable knowledge regarding immigrants' psychosocial challenges in general. We followed these steps from Brown and Clark (2006); we read through all the interviews; then we framed the themes; followed by a discussion between the two researchers; lastly, 
we named the themes. We used a combination of an inductive and a theoretical approach; we kept the framework of Bronfenbrenner as the main theoretical background theory, but then adopted an explorative perspective instead of trying to fit the data to pre-existing coding frames. Additionally, a latent rather than a semantic approach was used, i.e., identifying underlying ideas, assumptions and conceptualizations was more important than finding explicit or surface meanings. Only two themes were clearly inductively identified, i.e., Ethnicity-based bullying and External helpers. Any disagreement regarding the interpretation of the data was resolved by another new read-through. Only a few times a new read through was necessary, and since the disagreements was solved after this second read through, the third person, which was available in case of serious disagreement, was not involved.

For our first research question regarding experiences and interpretation of bullying behaviour, we identified two themes: Ethnicity-based bullying and Vulnerable attitudes. For our second research question, which concerned parents' experiences of how the school handled the bullying case and home-school cooperation, we identified three themes in total: lack of understanding, knowledge, and a plan for the next steps; information, acknowledgment, and trust; and external helpers. Finally, three themes related to our third research question about parents' experiences of cooperation and communication with other parents emerged: contact but avoidance of making bullying a topic, avoidance of cooperation, and avoidance of contact with minority parents in general.

The confidentiality of the participating parents was ensured by removing identifiable information (e.g., using codes instead of names for all individuals). NVivo 11, which is a qualitative data analysis software, was used to store and sort the data.

\section{Results}

In the following, the results for each research question are presented separately, with an introductory sum-up for each question.

\section{Parents' Experiences and Understanding of the Bullying Behaviour}

After being shown the definition of bullying, the parents confirmed that what their child was exposed to could be characterized as bullying. Thus, all the parents in our study regarded many of the situations their children experienced as bullying. It was both physical and relational bullying, in addition to cyberbullying. The minority parents (Sami and immigrant parents) also had opinions and assumptions regarding why their children were being bullied.

\section{Ethnicity-Based Bullying}

Both the Sami parents and three of the five immigrant parents reported that their children had received comments that were clearly aimed at their appearance, e.g., their skin colour, or their comprehension of the Norwegian language:

They said he was black. Even if he's not black, he's brighter than me.

Sometimes, it was, however, not explicit what the reason behind the bullying was, the immigrant parents tended anyway to characterize the bullying as racist or ethnicity-based:

Sometimes I thought it was because we were from another country. He doesn't have good language...I think it was because of the language.

These parents also commented on episodes where their children had received comments related to their country of origin and their classmates' negative associations with that country, such as the following:

They say things like "Tyskerjævel (bloody German)

I'll kill your dad; I'll kill your family."

Thus, the immigrant parents and also the Sami parents in our study were more specific than the ethnic Norwegian parents about explanations or causes of the bullying behaviour. Some bullying statements and cases were clearly related to ethnicity.

\section{Vulnerable Attitudes}

Statements such as "He does not have good language... I thought it was because of language..." may also imply that the parents have a sense of vulnerability. It seems that they easily think that if their child experience negative actions, like for example exclusion, it is because the child has poor language, different skin colour, or religion. Opinions such as "It is about shutting (the ethnic group) out..." also seem to suggest that the immigrant parent has an expectation that exclusion of the ethnic group is the norm and that those who are non-Norwegian are vulnerable.

The ethnic Norwegian parents described the bullying situations mostly as relational bullying, as in being excluded from the peer group without understanding why. They seemed less vulnerable than the immigrant parents, but statements like "She was sent out in the cold" and "The others formed a tight, exclusive group" were uttered by many of the Norwegian parents. 


\section{Parents Experiences of How the School Handled the Bullying Case and Home-School Cooperation}

The Norwegian parents did not seem to be very satisfied with how the school handled the case or with their cooperation with other parents. Only one of them said that she trusted the school to make a good investigation of the case. Two out of the five immigrant parents also felt it took some time before the school took action, but they were overall more satisfied than the Norwegian parents with cooperation, information and how the school handled the case; three immigrant parents felt they were listened to.

\section{Lack of Understanding, Knowledge, and a Plan for the Next Steps}

The Norwegian parents in our study had mostly negative experiences with how the school responded. One parent said, "They lack understanding and knowledge... it is not ill will...", while another expressed that "They should have taken it seriously earlier... it took years before the concept of bullying was used; first they said it is only small fights between the guys.. We asked back then for a plan to address it, then this just came: 'it is a conflict'."

Many of the parents also experienced that they were not taken seriously when they discussed their case with the school. These parents also felt that the case was poorly investigated before a conclusion was made and that the school did not seriously examine all aspects of the case. In one case where the situation was very complex and all the involved students experienced both to be targets of bullying and they were also perpetrators of bullying, one parent said: "based on allegations from one girl and her parents, the school described our daughter as a bully and even threatened us with reporting the incident to the police. They did not investigate, they just concluded." Only one Norwegian parent seemed to be happy with the way she was met, she also said that her son became less anxious after they told the teacher about the bullying, and the school started working with the case. The rest of the parents expressed a lack of trust regarding teachers' competencies and said that teachers did not know how to intervene. They also said that the school did not return their calls, that the teachers only believed their own version of the events. Even if this was true also for two immigrant parents; at least they felt it took time before the school took action, they were overall more satisfied than the Norwegian parents with cooperation, information and how the school handled the case. Three immigrant parents expressed that they felt they were listened to. However, the majority of the parents in our study seemed to think that teacher-student relationships were poor and that there was a lack of classroom management.
Information, Acknowledgment, and Trust

The Norwegian parents expressed that they felt they received little information about how the case was handled or what measures were taken. One parent said: "I wanted to be involved, but the school never wanted me to be." The immigrant parents, however, had a more positive experience overall with how the school handled the case, especially in regard to information. One parent said,

They helped a lot... They called at once to give information... They asked if I would like a meeting, they (the teacher) contacted the parents (of the bully) and the head teacher and he (the bully) apologized...

Though one parent expressed satisfaction with the school's response, saying, "The school reacts very fast...", most parents seemed to experience mistrust and did not feel acknowledged. One said, "It was like talking to a wall at first." And "we felt that they regarded us as very annoying." Another parent felt that the school did not believe what they said at first and that it took a long time before there was any response at all: "No one believed us, no one did anything.. It took a long time before we heard something." However, when they finally got a response, they felt that they were listened to: "The head teacher listened to us." There seemed to be a loss of confidence regarding whether the school would act at once among both majority and minority parents.

\section{External Helpers}

There seemed, however, to be trust in helpers outside the school. When the topic of help from the Educational Psychology Service (EPS) was raised, one parent stated, "He [the person from EPS] is very accomplished. We saw a change very fast." However, it was the parents that had to take the initiative to receive help from EPS: "The principal contacted EPS, but I asked the principal to do it..." Only two immigrant parents commented on this theme.

\section{Parents' Experiences of Cooperation and Communication with Other Parents}

Our results show that parents did not talk about the bullying with each other and that the school did not do anything to make it a topic of discussion among them. There also seemed to be a lack of shared perspective among the parents, who all had different versions of the truth. Additionally, immigrant parents felt that ethnic majority parents had no interest in collaborating and communicating with them. In the interviews we conducted, we did not find reports of positive or successful cooperation between parents. 


\section{Contact But Avoidance of Making Bullying a Topic}

One parent specifically noted, "I have good contact with others, but I did not tell them (about the bullying)." Another parent said that "I have not met with other parents at school to talk about this (the bullying)... We meet different places, but this topic (bullying) is not discussed." Since they never shared their own perspective, or listen to others, there was no opportunity to obtain a mutual understanding or a shared perspective. The parents all had different versions of the truth, basically based on their own child's experiences. Parents seemed to avoid talking about difficult relations between their children. This seemed to be applicable for both immigrant and non-immigrants.

\section{Avoidance of Cooperation}

In the case where 5 parents were involved in the same bullying case the bullying started the first year of secondary school, and since the children came from different primary schools, many of the parents were unknown to each other. They found it difficult to contact each other to arrange the first meeting to discuss the conflict among their children. The parents of the children in this class were very critical of how the school had handled the case, possibly because the case had been going on for a long time and the school, according to the parents, had made too little effort to solve it. "Nothing was explained to us, we were never encouraged to talk to each other. It was like the school needed someone they could blame, they were not interested in finding out what had happened." One also said: "I felt that we were many insecure individuals in that room".

There also seemed to be a lack of interest among some parents regarding others' perspectives, immigrant parents in particular, and they had different versions of the truth. One immigrant parent expressed the following: "One day, I thought now I must knock on their (another parent's) door. The parents said, 'We don't know, we do not know what is going on'. And I said, 'We have to find a solution'. They just said, 'no'; 'We do not know what to do with the boy'."

\section{Avoidance of Contact with Immigrant Parents in General}

Additionally, in regard to contact, there seemed to be a generally dismissive attitude towards or avoidance of immigrant parents specifically, at least from the perspective of the immigrant parents. One immigrant parent expressed it this way: "All other parents are much together, but me and my wife do not participate in the activities." Another one said: “...I tried to contact them; they did not contact me back." A third related the avoidance to the fact that they were immigrants: "You see it in the eyes, if they like you or want to contact you... I felt it was because we were not Norwegian... They do not see me; you feel it at once." This theme was not touched upon by the majority parents.

\section{Discussion}

Our main findings show differences between immigrant and non-immigrant parents regarding our two first research questions, while for the third the findings among immigrant and non-immigrant parents are more similar. Below we discuss the findings in relation to these headings: "Discrepancy of Understandings and Miscommunication Between School and Parents," "The Challenge of Vulnerability and Cultural Differences," and "The Importance, and Challenges, of ParentParent Collaboration."

\section{Discrepancy of Understandings and Miscommunication Between School and Parents}

Previous research has shown that there can be a large discrepancy between schools and parents regarding how they understand a case that concerns children in the same class (Westergård, 2010) and more specifically the school and the parents do not necessarily agree on identifying behaviour as "bullying" (Jahnsen \& Angelskår, 2018). Results from our study show that it at least took some time before school and parents agreed, as many parents, especially nonimmigrant parents, did not feel they were listened too when they approached the school about bullying. Our study also showed that this can lead to mistrust and conflicts between the parents and the school and discussions about the reasons for the complaints. Thus, our results are also partly in line with Hein (2012) as well as Harcourt and colleagues (2014), who found frequent miscommunication, misunderstanding and misjudgement of bullying situations between parents and the school. Exposure to bullying can cause serious harm, and it is of great importance that school staff take parents seriously when they express their concerns about bullying. The way the school handles the case may have serious implications for the relation and trust between families and the school. Thus, if the information the school gives to the parents is poor, parents may develop mistrust in the school. In our study, the parents felt, as in the study of Westergard (2010), that they were not taken seriously. According to Epstein's (2010) third type of parent influence, which concerns communication, there should be a regular exchange of information between schools and parents; this was indeed not the case in our study.

\section{The Challenge of Vulnerability and Cultural Differences}

Parents of children who experience social difficulties such as bullying are in a very vulnerable position (Støen et al., 
2018). It is painful to be the mother or father of a child who has no friends and is humiliated by other students. Our results showed that especially the immigrant parents found it painful to see that their child's differences were not accepted or appreciated in the peer group. Most of them interpreted the bullying or exclusion as connected to their child's ethnicity, religion or culture. The immigrant parents may also have negative experiences themselves, and therefore assume that their children experience something similar. This is in line with the study of Mishna (2004) that suggest that several factors influence ones' perception of what is going on and emphasize even more that to be met with understanding from the school staff is important.

Migration experience, in addition to having a child who is involved in bullying, might be emotionally challenging for parents, which again may make one more vulnerable regarding the school's handling of the bullying case and may make communication difficult. In our study, schools seem to be conscious of immigrant parents' need for support to some degree, or is it just that immigrant parents in Norway expect less from the school? According to Hofstede (1984) and Antony-Newman (2018), immigrant parents may see their role as different compared to Norwegian parents. For example, the role of school differs in different cultures. In some cultures, the school takes care of the children when they are at school, and the parents take care of them when they are at home; thus, cooperation is not expected. This may be because immigrant parents expect less from school; based on previous expectations from their home country they do not expect it to be any cooperation, this might have affected their answers in a way that they seem more satisfied than the majority parents in our study. On the other hand, or in addition to these cultural differences, immigrant parents may also feel more need for cooperation, as they are maybe more vulnerable because of the acculturation process (Berry, 1997).

Because of their vulnerable situation, or history, immigrant parents may also more easily interpret that the negative things that are happening are because of their ethnicity, this seems to be the case in our study, as they to a high degree explained both the bullying towards their children and the less interest from other parents to cooperate with them as ethnicity based (Tippet et al., 2010). It needs, however, to be emphasized that the behaviour or bullying might actually be based on ethnicity, even if race- or ethnic-based concepts are not what is explicitly used; thus, it is not only about interpretation; the ethnic-based bullying might be the objective reality.

Thus, ethnicity-based bullying seems to be a relevant topic not only regarding how parents interpret behaviour towards their children but also how they interpret behaviour from other parents.

\section{The Importance, and Challenges, of Parent-Parent Collaboration}

The parents in our study, both immigrant and non-immigrants, felt insecure about contacting other parents. Not knowing the other parents made it difficult to contact them, and the schools in our study had no strategy for cooperation between parents in bullying cases. This was especially true in the case in a lower secondary school where 5 parents, whose children were involved in the same bullying case, were interviewed. The bullying started the first year of lower secondary school, and since the children came from different primary schools, many of the parents were unknown to each other. They found it difficult to contact each other to arrange the first meeting to discuss the negative behaviours among their children. The parents of the children in this class were very critical of how the school had handled the case, possibly because the case had been going on for a long time and the school, according to the parents, had made too little effort to solve it. Even if our study, following Moorman Kim and Sheridan (2015), is more concerned with the relational aspect of parent involvement, it is possible that schools' outreach to parents that focuses more on structure, i.e., structured activities aiming to provide support for students' social and emotional wellbeing, could be of importance to improve collaboration between parents. As some immigrant parents interpreted the lack of interest from other parents as ethnicity-based, such measures might be especially important for immigrant parents. According to Bronfenbrenner's framework mutual contact, or collaboration, between all parents will be beneficial for the children.

Parents are role models for their children, and how they act towards and talk about their children's classmates and their parents has an impact on how the children themselves behave towards others (Nickerson et al., 2010). We do not know how explicitly the information we obtained from the parents is communicated to their children. Regardless of this, if the parents express negative attitudes or behave in an excluding way, this can contribute to the prolonging and strengthening pre-existing conflicts between peers. In addition, as previous research shows, children who have parents that actively support them regarding school related issues, have better peer relations, than those who have parents that do not support their children (Kirkhaug et al., 2013).

\section{Conclusion}

One important microsystem in Bronfenbrenner's model is the parents, and in this study, we especially investigated parents' experiences regarding bullying cases, cooperation with the school and cooperation with other parents; thus, we also touched upon the meso level (Bronfenbrenner, 1979). As we 
included immigrant parents in our study, we also included the macro level factor. Our results regarding bullying cases that were characterized as difficult to solve showed that most of the parents were not satisfied with how the schools handled the bullying cases, and, except from some immigrant parents, many parents felt that the school did not take them seriously.

Our results also showed that communicating and establishing relations with other parents were difficult tasks. Following Bronfenbrenner's model, both are important for the child. The meso level reflects the relations among the child's different settings and environments; thus, the relations between parents and between parents and teachers play an important role in the handling of bullying cases and thereby influence a child's life. Children can rarely resolve bullying cases themselves; they are dependent on the adults around them. As Liu and colleagues (2019) emphasize, it is important to involve parents in both addressing bullying and in following up after resolution of the case.

\section{Limitations and Future Research}

First, there is a risk in our study of social desirability bias, as all our data were collected through interviews. In addition, we should have in mind that the cases we investigated were characterized as problematic, or difficult to solve; thus, there might be said to be a sampling bias; i.e., we interviewed mostly "unhappy" parents. It is, however, natural that the parents are unhappy when their child is bullied; our main goal was thus to capture what the parents' experienced and what their "unhappiness" was related to. Second, some of the immigrant parents' Norwegian language skills were poor, thus the researchers' interpretation of what was meant might be biased, also the use of professional interpreters during the interviews, might have biased the results as it is challenging to preserve the original meaning when translating from a foreign language into Norwegian through a second person. Third, it might be seen as a leading question that we asked the parents with another ethnic origin if the bullying was due to race or ethnicity; thus, our results may be biased also because of this. We saw it, however, as necessary to ask directly about this as it might be difficult to talk about. Fourth, that five parents were involved in the same bullying case may be seen as a limitation, and a larger number of informants could have provided a better picture. Also, lumping the immigrant parents in one group when comparing is a major limitation; it might not always be meaningful as the members of this group are also very diverse. However, they have the migration experience in common and it was necessary to do for the current study based on the number available families to interview. Moreover, in qualitative research in general, generalization of the findings is not among the aims, and the results have identified important areas that can be used to improve and develop, especially the cooperation between the school and parents. As our study and previous studies have shown how problematic cooperation between the school and parents may be, we need future studies investigating successful parental involvement experiences. Moreover, the categories in the present study can be used as a starting point for development of quantitative surveys on this topic.

Regarding bullying cases and with the bioecological framework in mind, interviews with parents of the bullies should be conducted in future studies, and it could furthermore be interesting to explore one bullying case from different perspectives: parents, school leaders, teachers, targets of the bullying, and the perpetrators of bullying.

Last, more evidence is needed regarding ethnicity-based bullying specifically so that preventive and responsive interventions can be targeted to safeguard all those who experience it, including those who are ethnic minorities.

\section{Practical Implications}

Against the backdrop of the bioecological framework and to be in a position to develop effective prevention and intervention strategies, it is imperative that all those involved in both research and work with bullying cases understand the different complex systems in which bullying occurs and how these systems may interact. Our results point to the importance of school's contribution to better cooperation between parents regarding bullying cases. This can be done through creating arenas for communication between parents. Schools should establish structures such as discussion groups, cafes and other activities, especially ones that serve immigrant parents, as ethnicity-based bullying has its roots in groupbased prejudice.

In addition, our results emphasize the importance of taking into account the culture and migrant background of immigrant parents and the fact that they might be in a vulnerable situation because of previous loss. There is a need for interventions that address bullying at the school and community levels rather than, or in addition to, the individual level. This is especially important for ethnicity-based bullying, as this type of bullying reflects wider social problems of discrimination.

Home-school cooperation is necessary for both preventing and stopping bullying, as it leads to common and consistent strategies regarding how to respond to negative behaviour. Parent involvement can be strengthened by trusting, open and frequent communication. It is important to always listen to parents when they have a concern about their child; they have a right to be heard and to participate in matters that concern their children. The school should provide parents with information about how the case is handled and acknowledge parents' worries. It should be noted that 
parents of perpetrators and targets of bullying may feel especially vulnerable. Thus, schools must establish strategies for communication and relationship building before there is a conflict; a strong pattern of communication is crucial when there is a conflict situation such as a bullying case.

Emphasis should also be placed on home-school cooperation regarding bullying in preservice and in-service teacher education. Also, for clinical psychologists, it is important to be conscious in the importance of improving the relation between parents and schools. Recommendations for their work are to increase client's interest for the foreign, emphasize the importance of understanding others situation, and also to increase the consciousness of how better collaboration can help the children, as reflected in Bronfenbrenner's framework.

Funding Open access funding provided by University Of Stavanger.

\section{Declarations}

Conflict of Interest The authors declare no competing interests.

Open Access This article is licensed under a Creative Commons Attribution 4.0 International License, which permits use, sharing, adaptation, distribution and reproduction in any medium or format, as long as you give appropriate credit to the original author(s) and the source, provide a link to the Creative Commons licence, and indicate if changes were made. The images or other third party material in this article are included in the article's Creative Commons licence, unless indicated otherwise in a credit line to the material. If material is not included in the article's Creative Commons licence and your intended use is not permitted by statutory regulation or exceeds the permitted use, you will need to obtain permission directly from the copyright holder. To view a copy of this licence, visit http://creativecommons.org/licenses/by/4.0/.

\section{References}

Anthony-Newman, M. (2018). Parental involvement of immigrant parents: A meta-synthesis. Educational Review, 71, 3(362-381): https://doi.org/10.1080/00131911.2017.1423278

Baldry, A. C., \& Farrington, D. P. (2000). Bullies and delinquents: Personal characteristics and parental styles. Journal of Community and Applied Social Psychology, 10(1), 17-31. https://doi.org/10. 1002/(SICI)1099-1298(200001/02)10:1\%3c17::AID-CASP526\% 3e3.0.CO;2-M

Bernstein, J., \& Watson, M. (1997). Children who are targets of bullying: A victim pattern. Journal of Interpersonal Violence, 12(4), 483-498.

Berry, J. (1997). Immigration, acculturation, and adaptation. Applied Psychology: An International Review, 46, 5-34.

Borg, M. G. (1998). The emotional reactions of school bullies and their victims. Educational Psychology, 18(4), 433-444.

Boulton, M. J. (1997). Teachers' views on bullying: Definitions, attitudes and ability to cope. The British Journal of Educational Psychology, 67, 223-233.

Braun, V., \& Clarke, V. (2006). Using thematic analysis in psychology. Qualitative Research in Psychology, 3 (2). p. 77-101.

Bronfenbrenner, U. (1979). The ecology of human development: Experiments by nature and design. Harvard University Press.
Bronfenbrenner, U. (2005). Making human beings human: Bioecological Perspectives on human development. Sage.

Cherng, H. Y. (2016). Is all classroom conduct equal? Teacher contact with parents of racial/ethnic minority and immigrant adolescents. Teacher College Record 118.

Craig, W., et al. (2009). A cross-national profile of bullying and victimization among adolescents in 40 countries. International Journal of Public Health, 54, 2016-2224.

Epstein, J. L. (2010). School, family and community partnership: Preparing educators and improving schools (2nd ed.). Westview Press.

Espelage, D. L., \& Swearer, S. M. (Eds.). (2004). Bullying in American schools: A sosio-ecological perspective on prevention and intervention. Lawrence Erlbaum.

Fandrem, H., Strohmeier, D., \& Roland, E. (2009). Bullying and victimization among native and immigrant adolescents in Norway. The Journal of Early Adolescence, 29(6), 898-923.

Fandrem, H., Strohmeier, D., Caravita, S. \& Stefanek, E. (2021). Migration and bullying. In: P. K. Smith and J. O'Higgins Norman (Eds.). The Wiley Blackwell Handbook of Bullying. A comprehensive and International Review of Research and Intervention. Volume 1, Chapter 20 (pp 361-378), Wiley Blackwell.

Flaspohler, P., Elfstrom, J., Vanderzee, K., Sink, H., \& Birchmeier, Z. (2009). Stand by me: The effects of peer and teacher support in mitigating impact of bullying on quality of life. Psychology in the Schools, 46(7), 636-649.

Farrington, C. A., Roderick, M., Allensworth, E., Nagaoka, J., Keyes, T. S., Johnson, D. W., \& Beechum, N. O. (2012). Teaching adolescents to become learners. The role of noncognitive factors in shaping school performance: A critical literature review. University of Chicago Consortium on Chicago School Research.

Georgiou, S., \& Stavrinides, P. (2013). Parenting at home and bullying at school. An International Journal, 16(2), 165-179.

Harcourt, S., et al. (2014). We were sad and we were angry: A systematic review of parents' perspectives on bullying. Child and Youth Care Forum, 43(3), 373-391.

Hein, N. (2012). Foraldrepositioner i elevmobning. Aarhus, Aarhus Universitet. Ph.d.

Hein, N. (2016). new perspectives on the positioning of parents in children's bullying at school. British Journal of Sociology of Education. https://doi.org/10.1080/01425692.2016.1251305

Hofstede, G. (1984). Culture's consequences: International differences in work-related values. Sage.

Holt, M. K., Kaufman Kantor, G. \& Finkelhor, D. (2007). Parent/ Child Concordance about Bullying Involvement and Family Characteristics Related to Bullying and Peer Victimization. Journal of school violence, 8(1), p.42-63. https://doi.org/10.1080/ 15388220802067813

Jahnsen, H., \& Angelskaar, T. (2018). «Den kommunikasjonen - jeg kunne gjort det annerledes. Om rektors rolle i mobbesaker [«That communication - I could have done it differently. About principals' roles in bullying cases"]. In J. Støen, H Fandrem \& E. Roland (Eds.), Stemmer i mobbesaker. Resultater og erfaringer fra Stigma-prosjektet. [Voices in bullying cases. Results and experiences from the Stigma-project]. Bergen: Fagbokforlaget.

Kanetsuna, T. (2016). Comparisons between English bullying and Japanese ijime. In P. K. Smith, K. Kwak, \& Y. Toda (Eds.), School bullying in different cultures: Eastern and western perspective (pp. 153-169). Cambridge University Press.

Kirkhaug, B., Drugli, M. B., Klockner, C. A., \& Morch, W.-T. (2013). Association between parental involvement in school and child conduct, social, and internalizing problems: Teacher report. Educational Research and Evaluation, 19(4), 346-361.

Ladd, G. W., \& Kochenderfer Ladd, B. J. (1998). Parenting behaviors and the parent-child relationship. Correlates of peer victimization in kindergarten? Developmental Psychology, 34(6), 1450-1458. https://doi.org/10.1037/0012-1649.34.6.1450 
Liu, D., Wong, S. D. \& Roland, D. (2019). The Family School Linkage in addressing bullying in Hong Kong: A sociocultural perspective. Chinese Education \& Society, 51, 6, 462-475, https://doi.org/10. 1080/10611932.2018.1570799

Nordhagen, R., Nielsen, A., Stigum, H., \& Kohler, L. (2005). Parental reported bullying among Nordic children: A population-based study. Child: Care, Health and Development, 31(6), 693-701. https://doi.org/10.1111/j.1365-2214.2005.00559.x

Mishna, F. (2004). A Qualitative Study of Bullying from Multiple Perspectives. Children \& Schools 26 (4), 234-247, https://doi.org/ $10.1093 / \mathrm{cs} / 26.4 .234$

Mishna, F., Scarcello, I., Pepler, D., \& Wiener, J. (2005). Teachers' understanding of bullying. Canadian Journal of Education, 28(4), 718-738.

Mishna, F., Pepler, D., \& Winer, J. (2006). Factors associated with perceptions and responses to bullying situations by children, parents, teachers and principals. Victims and Offenders, 1, 255-288. https://doi.org/10.1080/15564880600626163

Meehan, A., Axisa, G. B., Bäckström, B., de Almeida, S., Friant, N., Johannessen, Ø. L. \& Roman, M. (2021). Context rules! Top-level education policies for newly arrived migrant students across six European countries. European Journal of Educational Psychology, 2(2). https://doi.org/10.1016/j.ijedro.2021.100046

Moorman Kim, E. \& Sheridan, S. (2015). Foundational Aspects of Family-School Connections: Definitions, Conceptual Frameworks, and Research Needs. In: Sheridan S., Moorman Kim E. (eds) Foundational Aspects of Family-School Partnership Research. Research on Family-School Partnerships, vol 1. Springer, Cham. https://doi.org/10.1007/978-3-319-13838-1_1

Nickerson, A. B., Merke, D., \& Osborne-Oliver, K. M. (2010). Parents -child relationship and bullying. In S. R. Jimerson, S. M. Swearer, \& D. Espelage (Eds.), Handbook of bullying in schools: An international perspective (pp. 187-197). Routledge.

OECD. (2015). Immigrant students at school: Easing the journey towards integration. OECD Publishing. https://doi.org/10.1787/ 9789264249509-en

Olweus, D. (1974). Hakkekyllinger og skolebøller. Forskning om skolemobbing. Oslo. Cappelen.

Olweus, D. (1980). Familial and Temperamental Determinants of Aggressive Behavior in Adolescent Boys: A Causal Analysis. Developmental Psychology 16: 644-660.

Peguero, A. A. \& Hong, J. S. (2020). School bullying: Youth vulnerability, marginalization and victimization. Springer Series on Child and Familiy studies. Switzerland: Sringer.

Pellegrino, J., \& Hilton, M. (2012). Education for life and work: Developing transferable knowledge and skills in the 21st century. National Academies Press.

Rivara, F. \& Le Menestrel, S. M. (2016). Individuals withn social contexts. In: Rivara F, Le Menestrel S (eds.), Preventing bullying through science, policy, and practice. The National Academies Press, Washington, DC, pp 69-112.

Rogers, W. \& Lange M. M. (2013). Rethinking the Vulnerability of Minority Populations in Research. American Journal of Public Health 103 (12), 2141-2146. https://doi.org/10.2105/AJPH.2012.301200

Roland, E., \& Idsoe, T. (2001). Aggression and bullying. Aggressive Behavior, 27(6), 446.
Sawyer, J. L., Mishna, F., Pepler, D., \& Wiener, J. (2011). The missing voice: Parents' perspectives of bullying. Children and Youth Services Review, 33(10), 1795-1803.

Stevens, G. W., Boer, M., Titzmann, P. F., Cosma, A., \& Walsh, S. D. (2020). Immigration status and bullying victimization: Associations across national and school contexts. Journal of Applied Developmental Psychology, 66, 101075

Smith, P. K., \& Myron-Wilson, R. (1998). Parenting and school bullying. Clinical Child Psychology and Psychiatry, 3, 405-417.Stitt, N. M. and Brooks, N. J. (2014) Reconceptualizing parent involvement parent as accomplice or parent as partner? The University of Chicago Press Journals, 11 (1).

Thornberg, R., \& Delby, H. (2019). How do secondary school students explain bullying? Educational Research. https://doi.org/10.1080/ 00131881.2019 .1600376

Skeie, G. \& Fandrem, H. (2021). Fordommer, mobbing og religionsdidaktikk. I: M. von der Lippe (red.): Fordommer i Skolen: Gruppekontruksjoner, Utenforskap og Inkludering [Prejudice in school: Group constructions, outsiders and inclusion], Chapter 10. Oslo: Universitetsforlaget.

Søndergaard, D. (2020) Bullying and Parents In: D. T. Cook: The sage encyclopedia of children and childhood studies, p. 167-169. Thousand Oaks, California: Sage Publications.

Stitt, N. M., \& Brooks, N. J (2014). Reconceptualizing Parent Involvement. Parent as Accomplice or Parent as Partner? Schools, 11 (1). https://doi.org/10.1086/675750

Støen, J., Fandrem, H. og Roland, R. (2018). Mobbing i et systemperspektiv. I: J. Støen, H. Fandrem og E. Roland, Stemmer i mobbesaker: resultater og erfaringer fra Stigmaprosjektet. Bergen: Fagbokforlaget.

Tippett, N., Houlston, C., \& Smith, P. K. (2010). Prevention and response to identity-based bullying among local authorities in England, Scotland and Wales. Retrieved from London: https:// www.equalityhumanrights.com/sites/default/files/research-report64-prevention-and-response-to-identity-based-bullying-amonglocal-authorities-in-england-scotland-and-wales.pdf

Troy, M., \& Sroufe, L. A. (1987). Victimization among preschoolers: Role of attachment relationship history. Journal of the American Academy of Child and Adolescent Psychiatry, 2, 166-171.

Turney, K., \& Kao, G. (2009). Barriers to school involvement: Are immigrant parents disadvantaged? The Journal of Educational Research, 102(4), 257-271.

Wendelborg, C. (2020). Mobbing og arbeidsro i skolen. Analyse av Elevundersøkelsen 2020/21 [Bullying and work in peace. An analysis of the National student survey 2020/2021]. Trondheim: NTNU, Samfunnsforskning.

Westergard, E. (2004). Parental disillusionment with school: Prevalence and relationship with demographic variables, and phase, size and location of school. Scandinavian Journal of Educational Research, 48(2), 189-204. https://doi.org/10.1080/ 0031383042000198521

Westergard, E. (2010). Parental disillusionment with school: Prevalence, correlates, development and prevention. Stavanger Universitetet i Stavanger. 